\section{Emergency Preparedness and Response to the COVID-19 Pandemic: Our Experience from the Emergency Depart- ment of a Tertiary Care Hospital in Pakistan}

Sir,

Severe acute respiratory syndrome coronavirus 2 (SARS-CoV-2) causing coronavirus disease 2019 (COVID-19) has proven to bea nightmare for the entire world. The degree of chaos, that it has created, has given us a reason to write about our experiences as a healthcare professional from Pakistan, a low-middle income country (LMIC). On $31^{\text {st }}$ December 2019, Chinese authorities reported increase in incidence of severe pneumonia in Wuhan city, Hubei province of China. ${ }^{1,2} \mathrm{~A}$ week later, they confirmed that they had identified a new corona virus, which is a family of micro RNA respiratory viruses that includes the common cold, and other viruses such as severe acute respiratory syndrome (SARS) and Middle-east respiratory syndrome (MERS) viruses. This new virus was temporarily named "2019-nCoV". ${ }^{3}$ This report to the World Health Organization (WHO) raised a global public health concern because this was the third outbreak of a corona virus associated acute respiratory illness. Although 2019-nCoV has not been included in the WHO blueprint list of priority diseases yet, MERS-CoV and SARS-CoV, which are already included in this list, are both coronaviruses that have led to global outbreaks in 2003 and 2012, respectively. ${ }^{4-6}$

The outbreak that started in China, in a very short timeframe, has involved many other countries. For an LMIC, like Pakistan, it is a disaster. We already work in a compromised setup with limited healthcare resources. Here, majority of the population is deprived of basic necessities of life. Fighting with COVID-19 is a real challenge for us. First case of COVID positive patient was reported officially in the end of February 2020 in Karachi. Only 3 deaths were reported till mid of March 2020 due to COVID-19; and then there was sudden rapid rise in new cases, reported from almost every province of Pakistan. One week later, on $23^{\text {rd }}$ March, 2020 the government announced a complete lockdown of the country.

Given large-scale spreading of this virus around the world, the priority was to identify infected cases and contain possible spreading routes. Here, the biggest challenge was to stop the spread and judicious utilisation of scarce healthcare facilities for the affected population. It was a time for the government to minutely focus on the healthcare system - whether public, private or a combination thereof.
The Aga Khan University Hospital (AKUH), Karachi, where we work, is one of the best tertiary care hospitals and is known for its outstanding healthcare services. It is a 700-bedded hospital. Emergency preparedness and response for providing appropriate care to the patients suspected of having corona virus-associated acute respiratory illness was the need of the hour. Our hospital, as a whole, had to quickly develop strong and effective strategies in order to cope up with the pandemic at its doorstep.

Initially, when the burden of disease was low, the Emergency Department (ED) divided the triage area into COVID-19 and non-COVID-19 sections, so that the patient cohorts could be kept separated. Patients were directed to community health centre (CHC), an area of family medicine clinics, for testing of COVID after screening. This was done in collaboration with the government of Pakistan. As the number of cases increased, AKUH set a field triage for screening purpose outside the main ED. In addition, a COVID triage tool was developed for both adult and pediatric patients to streamline the screening and expedite the admission process. The confirmed COVID patients were admitted in single room for strict isolation for 14 days as pergovernment and hospital policy.

With the passage of time, there was rapid influx of patients coming for COVID testing. In the initial stage of outbreak, we were testing every screened positive patient; soon, we were faced with the shortage of testing kits. At that moment, we decided to reserve COVID testing only for our AKUH staff and sicker patients requiring admission. Moreover, we started discharging both suspected and confirmed COVID patients from ED, who were clinically stable with strict home isolation instructions or to government-designated hospitals.

Meanwhile, the hospital management converted its acute care unit (ACU), a 10-bedded unit previously used to accommodate patients requiring high dependency care when inpatient intensive care/high dependency care units were full to capacity into complete negative pressure area, which was dedicated to COVID positive patients. This unit was built in close vicinity of ED to streamline the flow of critical patients.

The ED was further divided into COVID and non-COVID areas with further stratification of COVID area into respiratory and non-respiratory unit, based on whetherpatients require respiratory intervention in the form of high flow oxygen, nebulisation, noninvasive or invasive mechanical ventilation. Clinical decision unit (CDU), an eight-bedded short stay unit, used for 24hour admission of emergency patients, was converted into negative pressure, unit specifically for COVID suspected patients with respiratory symptoms, named respiratory COVID unit (RCU). All critically ill patients were transferred to RCU after being assessed on the basis of emergency severity index (ESI) for prompt management at filter triage outside ED. Special protocols were developed for intubation and admission of COVID patients.

As we were concerned about safety of our staff, we reduced the 
duty hours of RCU staff posted there from 12 hours to 8 hours in order to minimise the duration of exposure. We also provided our staff with level III personal protective equipments (PPEs) at RCU and level II PPEs at moderate risk areas of ED with proper teaching of donning and doffing. Those who failed N-95 mask fit test were notassigned to RCU; rather, we provided them respirators.

Apart from major redesigning in ED floor plan, work flow and clinical processes, the academic activities also underwent major improvisations. Since AKUH is a teaching and training hospital, we in the ED switched all lectures, grand rounds, and weekly core modules into virtual academic sessions. Though this is relatively compromised way of teaching to our ED residents, as there are no hands-on simulation workshops; but in this crucial time, this is the best possible alternative in order to continue educational activities.

Till date, we are working on the guidelines and policies that we developed initially; and modified asperthe change in the institutional policies based on the influx of suspected as well as confirmed COVID cases and increase in number of inpatient beds for such patients. Still we need to develop more extensive system at ED to handle the situation; as with the passage of time, we are receiving more critical patients; who are either suspected or confirmed COVID cases. The strategies may include changes in clinical guidelines in the management of critical patients, for example, turning COVID patients with respiratory distress into prone position, use of immunoglobulin extracted from plasma of previously COVID positive patients, etc.

In the end, we are hopeful that with these multi-faceted approaches, we will be more equipped in terms of flow processes as well as clinical knowledge to brave these difficult times more strategically and to provide safe care to these patients in a saferED.

\section{CONFLICT OF INTEREST:}

Authors declared no conflict of interest.

\section{AUTHORS' CONTRIBUTION:}

BA: Conceived the idea.

NA: Prepared the first draft.

AM: Reviewed the draftand made corrections.

\section{REFERENCES}

1. Organization WH. Novel Coronavirus (2019-nCOV) situation report-9, 29 January 2020. Geneva, Switzerland. 2020.

2. Munster VJ, Koopmans M, Doremalen VN, Riel DV, Vit ED. A novel coronavirus emerging in china-Key questions for impact assessment. N EnglJ Med 2020; 382(8):692-4.

3. Schwartz DA, Graham AL. Potential maternal and infant outcomes from coronavirus 2019-nCoV (SARS-CoV-Infecting pregnant women: Lessons from SARS, MERS, and other human coronavirus infections. Viruses 2020; 12(2):194.

4. Organization WH. Clinical management of severe acute respiratory infection when novel coronavirus (2019- nCoV) infection is suspected: interim guidance, 28 January 2020. World Health Organization, 2020.

5. Holshue ML, DeBolt C, Lindquist S, Lofy KH, Wiesman J, Bruce $\mathrm{H}$, et al. First case of 2019 novel coronavirus in the United States. N Engl J Med 2020; 382(10):929-36.

6. Wang W, Tang J, Wei F. Updated understanding of the outbreak of 2019 novel coronavirus (2019-nCoV) in Wuhan, China. J Med Virol 2020; 92(4):441-7.

Badar Afzal, Noman Ali and Asad Mian

The Aga Khan University Hospital, Karachi, Pakistan

Correspondence to: Dr. Noman Ali, The Aga Khan University Hospital, Stadium Road, Karachi, Pakistan

E-mail: noman.ali@aku.edu

Received: May 07, 2020; Revised: May 21, 2020;

Accepted: June 23, 2020

DOI: https://doi.org/10.29271/jcpsp.2020.JCPSPCR.CR72 